\title{
Neuroophthalmological Manifestations of Systemic Lymphomas
}

\author{
Hülya Gökmen Soysal ${ }^{1 *}$ and Ayla Gökmen² \\ ${ }^{1}$ Department of Ophthalmology, Kafkas University, Faculty of Medicine, Turkey \\ ${ }^{2}$ Department of Hematology-Oncology, Ankara Medicana Hospital, Turkey \\ *Corresponding author: Hülya Gökmen Soysal, Department of Ophthalmology, Kafkas University, Faculty of Medicine, Turkey.
}

Submission: 侮 June 25, 2018; Published: 觜 August 27, 2018

\begin{abstract}
Background: We aimed to present neuroophthalmological manifestations that seen in patients with systemic lymphoma.

Methods: All patients with systemic lymphoma that consulted due to ophthalmologic problems were evaluated for neuroophthalmological abnormalities. Clinical findings were recorded if any abnormality was detected.

Results: Several neuroophthalmological manifestations were founded in 16 patients. Symptoms were; ptosis, pain, diplopia and visual loss. Signs were; ophthalmoplegia, pupillary abnormalities, ptosis, visual loss, and swollen optic disc. Involvement of optic nerve (4 cases), abducens nerve (5 cases), oculomotor nerve ( 3 cases) and multiple cranial nerves ( 7 cases) was detected. In 8 cases, positive cerebro spinal fluid citology or radiodiagnostic findings were present to consider central nervous system (CNS) involvement, while in 8 cases these findings were normal. Overt CNS involvement was occurred later in additional 3 cases.
\end{abstract}

Conclusion: Systemic lymphomas can cause neuroophthalmological manifestations during disease or, as a presenting sign of primary or recurrent lymphoma. These manifestations are usually precursors of central nervous system involvement. Early detection is important for reversal of symptoms, but the prognosis is usually not favorable.

Keywords: Lymphoma; Ophthalmoplegia; Optic nerve involvement

\section{Introduction}

Lymphomas are a heterogeneous group of malignancies of the lymphoid system. A variety of neuroophthalmological manifestations may accompany with Hodgkin or non-Hodgkin lymphomas. The incidence of central nervous system (CNS) involvement in lymphomas is increasing, due to longer survival as the result of more effective treatment and thus, the ophthalmologist has an increasing change of being involved with these patients $[1,2]$. In this study, we aimed to present the neuroophthalmological manifestations of systemic lymphomas that seen in a general oncology hospital.

\section{Material and Methods}

Within the 6 years period, patients with any type of systemic lymphoma that diagnosed and followed by Hematology-Oncology Department were consulted to ophthalmology clinic whenever ophthalmicproblemswerepresent. Full ophthalmologic examination was made to all patients. Among those, neuroophthalmological manifestations were selected and records were analyzed. Ocular or adnexal lymphomas were excluded, because we aimed to analyze the only indirect manifestations of systemic disease, other than ocular and orbital manifestations of direct primary involvement of the eye and orbit.

\section{Results}

Table 1: Neuroophthalmologic symptoms and number of cases that seen in lymphoma patients.

\begin{tabular}{|c|c|}
\hline Symptoms & Number of Cases \\
\hline Ptosis & 9 \\
\hline Pain & 7 \\
\hline Diplopia & 6 \\
\hline Visual loss & 4 \\
\hline
\end{tabular}

Various neuroophthalmological abnormalities were detected in 16 patients. The symptoms that recorded were; ptosis, pain, 
diplopia and visual loss. The findings that have been detected were; ophthalmoplegia, pupillary abnormalities (afferent pupillary defect, amorotic pupilla or unresponsiveness to light), ptosis, visual loss, and swollen disc. Table $1 \& 2$ shows neuroophthalmological symptoms and signs of the patients. Table 3 shows patient's characteristics for each case.

Table 2: Neuroophthalmologic findings and number of cases that seen in lymphoma patients.

\begin{tabular}{|c|c|}
\hline Neuroophthalmologic Findings & Number of Cases \\
\hline Ophthalmoplegia & 14 \\
\hline Pupillary abnormalities & 12 \\
\hline Ptosis & 9 \\
\hline Visual loss & 4 \\
\hline Swollen optic disc & 3 \\
\hline
\end{tabular}

Table 3: The list of patients and clinical characteristics.

\begin{tabular}{|c|c|c|c|c|c|c|c|c|}
\hline Case & Age-gender & $\begin{array}{c}\text { Involved } \\
\text { Cranial } \\
\text { Nerve }\end{array}$ & $\begin{array}{l}\text { Bilateral/ } \\
\text { Unilateral }\end{array}$ & Major Findings & CSF Cytology & CT-MRI & Treatment & Course \\
\hline 1 & $42 \mathrm{~F}$ & II & bilateral & Visual loss & - & $\begin{array}{l}\text { Optic nevre thic- } \\
\text { kening }\end{array}$ & RT & died \\
\hline 2 & $37 \mathrm{M}$ & II, VI & unilateral & $\begin{array}{l}\text { Visual loss, opht- } \\
\text { halmoplegia }\end{array}$ & - & Normal & RT, SC & $\begin{array}{l}\text { İmprovement, } \\
\text { died }\end{array}$ \\
\hline 3 & $36 \mathrm{~F}$ & II & unilateral & Visual loss & - & Normal & RT & İmprovement \\
\hline 4 & $53 \mathrm{M}$ & III, IV, VI & bilateral & ophthalmoplegia & - & Normal & IC, SC & İmprovement \\
\hline 5 & $34 \mathrm{~F}$ & II, III, IV, V ${ }_{1}, \mathrm{VI}$ & unilateral & $\begin{array}{l}\text { Visual loss, opht- } \\
\text { halmoplegia, pain }\end{array}$ & - & $\begin{array}{l}\text { Mass in caver- } \\
\text { nous sinus and } \\
\text { orbital apex }\end{array}$ & $\mathrm{RT}, \mathrm{SC}$ & died \\
\hline 6 & $46 \mathrm{M}$ & III, IV, $\mathrm{V}_{1}, \mathrm{VI}$ & unilateral & $\begin{array}{l}\text { ophthalmoplegia, } \\
\text { pain }\end{array}$ & - & $\begin{array}{c}\text { Mass in caver- } \\
\text { nous sinus }\end{array}$ & RT, SC, IC & died \\
\hline 7 & $60 \mathrm{M}$ & III, IV, VI & unilateral & ophthalmoplegia & + & Normal & IC, RT & İmprovement \\
\hline 8 & $35 \mathrm{M}$ & III, IV, VI & unilateral & ophthalmoplegia & - & Normal & SC, RT & died \\
\hline 9 & $43 \mathrm{~F}$ & III, IV, VI & unilateral & ophthalmoplegia & + & $\begin{array}{l}\text { Leptomeningeal } \\
\text { thickening }\end{array}$ & IC, SC,RT & İmprovement \\
\hline 10 & $24 \mathrm{~F}$ & III & unilateral & ophthalmoplegia & + & Normal & IC, SC, RT & died \\
\hline 11 & $21 \mathrm{E}$ & III & unilateral & ophthalmoplegia & & Normal & SC, RT & İmprovement \\
\hline 12 & $44 \mathrm{E}$ & III & unilateral & ophthalmoplegia & + & Normal & IC, RT & İmprovement \\
\hline 13 & $39 \mathrm{M}$ & VI & unilateral & ophthalmoplegia & + & $\begin{array}{l}\text { Leptomeningeal } \\
\text { thickening }\end{array}$ & IC, RT, SC & İmprovement \\
\hline 14 & $51 \mathrm{~F}$ & VI & unilateral & ophthalmoplegia & - & Normal & RT & İmprovement \\
\hline 15 & $37 \mathrm{E}$ & VI & unilateral & ophthalmoplegia & - & Normal & SC, RT & died \\
\hline 16 & $21 \mathrm{M}$ & VI & unilateral & ophthalmoplegia & - & Normal & RT & İmprovement \\
\hline
\end{tabular}

F: Female; M: Male; RT: Radiation Therapy; SC: Systemic Chemotherapy; IC: Intrathecal Chemotherapy

Optic nerve involvement was founded in four patients. In one of them, simultaneous central retinal artery occlusion (CRAO) and venostasis retinopathy was present bilateraly (Case 1). Unilateral abducens palsy and optic neuritis was present in one, unilateral optic neuritis was present in one and orbital apex syndrome (Case 2) in one another. With the prompt treatment, improvement of vision was achieved in two of them. Lumbar puncture didn't reveal any malignant cells, but three of the patients were died with overt CNS involvement despite aggressive therapy.

Ophthalmoplegia were detected in 14 patients. Bilateral total ophthalmoplegia in one, unilateral total ophthalmoplegia in five patients was detected. In two of them, malignant cells were detected in cerebrospinal fluid (CSF) analysis, and after systemic and intratechal chemotherapy, the signs were markedly improved. In other two of them, a mass in cavernous sinus was detected. One of these patients with cavernous sinus syndrome has been diagnosed as Hodgkin lymphoma. In one patient with unilateral total ophthalmoplegia, CSF analysis or radiodiagnostic techniques didn't show any sign of CNS involvement, but 6 months later, patient died from leptomeningeal meningitis.

Isolated unilateral oculomotor nerve paralysis in three, patients, abducens nerve paralysis in four patients was determined. In 3 of 
them, CSF analysis was positive for lymphomatous involvement, MRI scan revealed leptomeningeal thickening in one. In 9 of 14 patients with ophthalmoplegia that were treated with systemic or intratechal chemotherapy or radiotherapy, marked improvement of symptoms was observed, but 6 of 14 patients were died of disease.

In 12 of 16 patients, these neuroophthalmologic manifestations developed in clinical systemic remission and were presenting signs of the recurrence. Findings suggesting CNS involvement were present only in 8 cases, but in additional 3 cases, salient CNS involvement was developed later.

\section{Case Reports}

\section{Case 1}

42 years old women, who has been diagnosed as NHL, was presented with bilateral, severe visual loss for two weeks, when she was under remission. Lumbar puncture, bone marrow examination and brain CT were all normal. On examination, visual acuity was no light perception in both eyes, both pupils were fixed and unresponsive to light. There was no extraocular motility disturbance. On fundus examination, ischemic whitening of the retina, increased venous tortuosity, cherry red spot appearance, scattered intraretinal and preretinal hemorrhages and swollen optic disc was detected in both eyes (Figure 1 \& 2). Orbital CT and MRI showed thickening of both optic nerves, and perineural enhancement was seen following contrast administration (Figure 3 ). Then the patient was diagnosed as, bilateral combined central retinal artery and vein oclusion due to optic nerve tumoral involvement and treated with orbital radiotherapy. Visual acuity didn't improve, and the patient was died 7 months after the optic nerve involvement

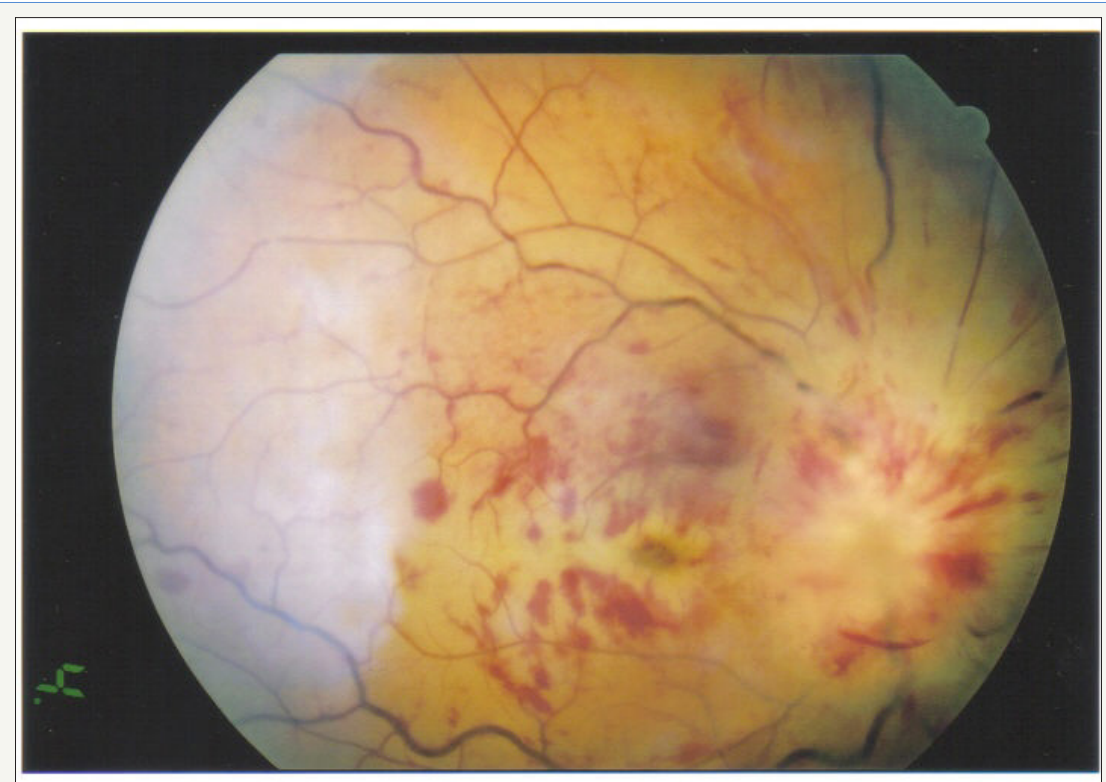

Figure 1: The right fundus of the case 1. Retinal oedema, cherry red spot appearance, venous stasis and swollen optic disc were seen.

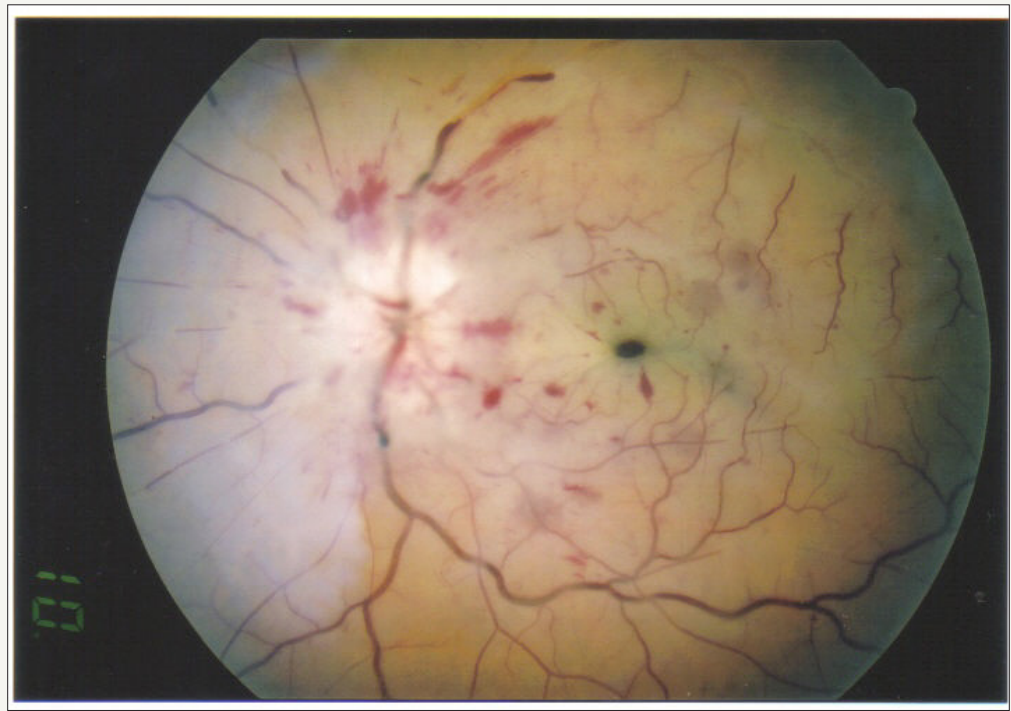

Figure 2: The left fundus of the same patient. 


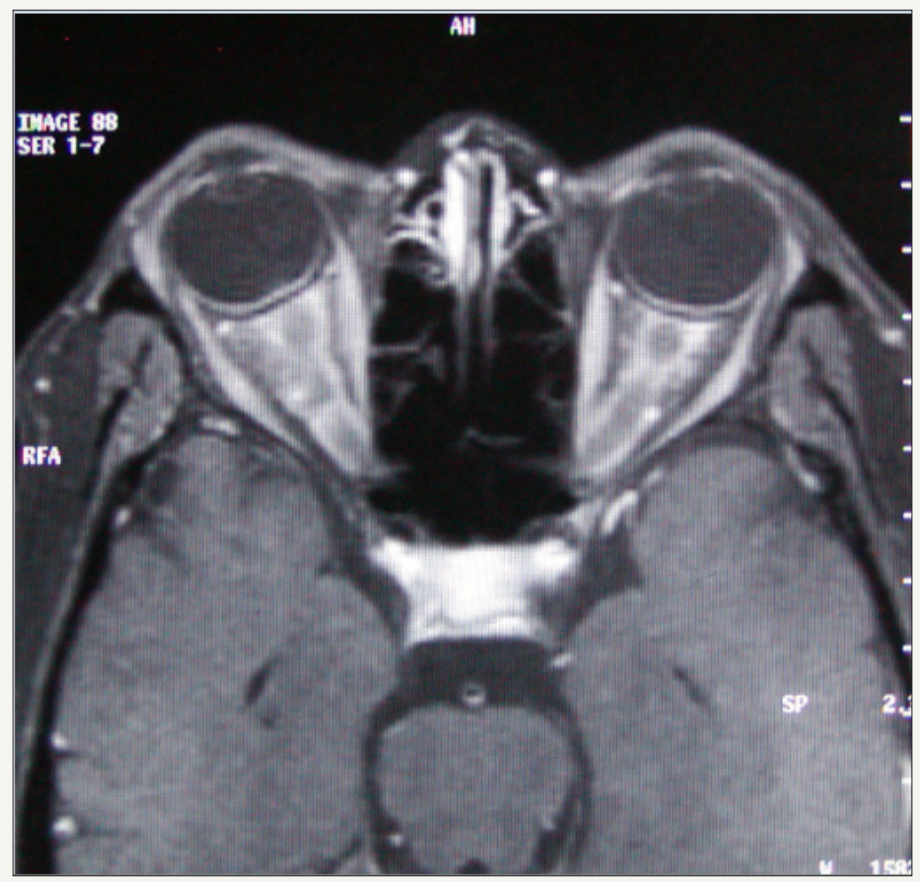

Figure 3: MRI scan of case 1. Thickened optic nerves and contrast enhancement of perineural tissue, more prominent on right side.

\section{Case 2}

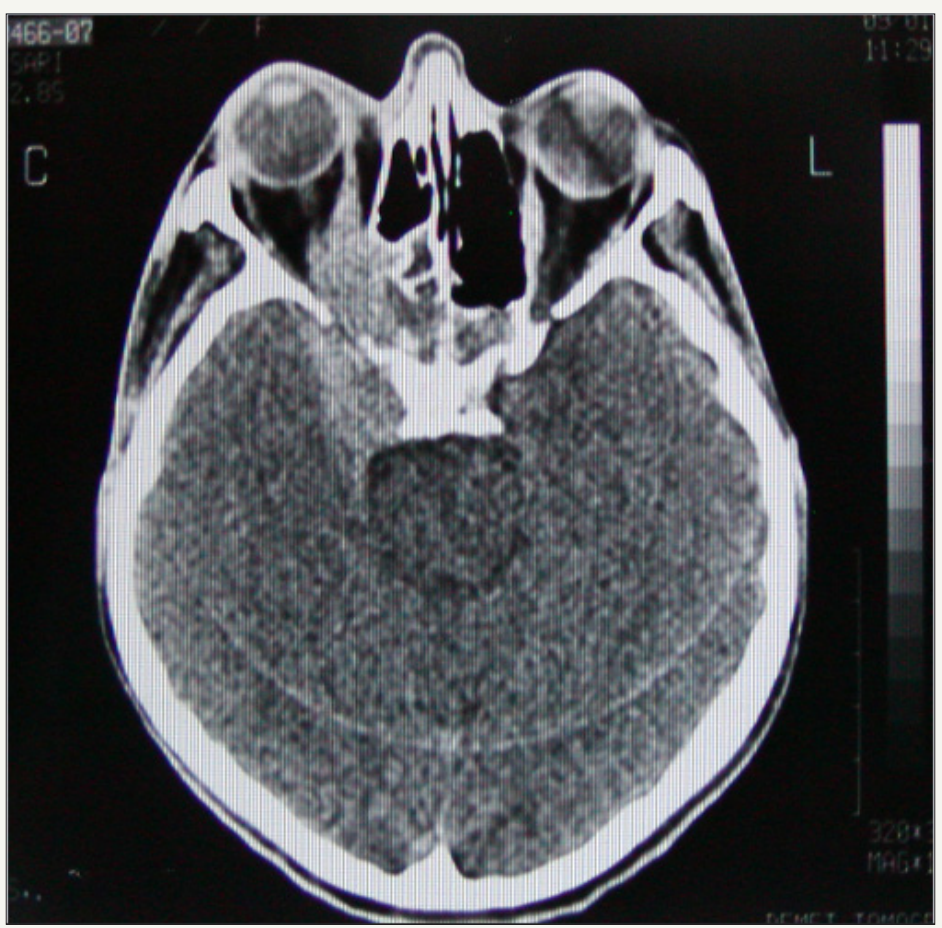

Figure 4: CT of case 5. A mass on the right cavernous sinus extending to orbital apex.

34 years old female patient noted binocular diplopia and right ptosis followed by severe visual loss on her right eye. She was diagnosed as Hodgkin lymphoma two years ago. Visual acuity was no light perception OD, 20/20 OS. Right pupil was dilated, and unreactive to light. There was complete ophthalmoplegia and ptosis OD, and normal ductions OS. No abnormality was detected on slit lamp and fundus examination. Facial motor function was normal. Cranial CT and MRI showed a large mass in the cavernous sinus, extending into orbital apex, sphenoid sinus and nasopharinx (Figure 4). CSF analysis was negative for malignant cells. A diagnostic biopsy from mass with nasopharengial approach was planned but patient refused surgical manipulations. Systemic and intratechal chemotherapy combination was administered, but she died of pulmonary infection. 


\section{Discussion}

Neuroophthalmological findings in lymphomas are not common, but there are increasing number of case reports in the literature. These reports are mostly about optic neuritis, ophthalmoplegias or anterior visual system involvement. To our knowledge, this is the first study including a series of neuroophthalmologic manifestations that seen in lymphomas, in English language literature.

Cranial and peripheral nerves may be affected in several ways, directly or indirectly in lymphoprolipherative disorders [3]. Abnormalities in cranial nerves II-X, and XII have been reported $[3,4]$. Cranial nerve involvement causing neuroophthalmological signs may be present with or without distinct CNS involvement in systemic lymphomas. It has been associated with lymphomatous infiltration, infections, neurotoxic drugs, radionecrosis and paraneoplasia [1]. Lymphomatous infiltration can be in a direct fashion and compress surrounding tissues. Sometimes menengial infiltration occurs and causes multiple cranial neuropathies. Rarely, lymphomatous infiltration will be angiotrophic and result in ischemic damage to the nerves [5].

The most important factor that causes neuroophthalmological abnormalities in lymphomas is CNS involvement. Although lymphomatous infiltration of cranial nerves doesn't indicate diffuse CNS involvement, lymphomatous meningitis typically causes multiple cranial nerve palsies which may include the optic and ocular motor nerves. Despite quite characteristic clinical findings, proof of the diagnosis, may be difficult. If malignant cells aren't sloughed into the CSF in sufficient quantities, cytologic examination will be unrevealing. Thus, the normal CSF findings don't rule out lymphomatous meningitis [6]. Because of the low yield of CSF analysis, repeated lumbar punctures with examination of large quantities of spinal fluid may be required before malignant cells are found $[6,7]$. It's reported that the sensivity of cytological diagnosis with one CSF examination was 54\% but increased to $91 \%$ with two lumbar punctures [8]. Similarly, CT or MRI scan may fail to show CNS involvement of lymphomas [9,10]. In this study, in 8 cases, no clue for CNS involvement was detected on CSF cytology or MRI scan. But, CNS involvement occurred later in 3 cases.

CNS involvement in NHL occurs in about $10 \%$ of cases, of those $5 \%$ will develop optic nerve infiltration. Although this usually occurs in established CNS disease, it may be a presenting symptom of the lymphoma or a manifestation of recurrence in patients in clinical remission [1,11]. Our three cases with optic nerve involvement were all in clinical remission. In one of these cases, CRAO was present. Central retinal vessel oclusion is a very rare event in systemic lymphomas. Cases with optic nerve involvement with CRAO reported in the literature [12,13]. Retinal artery occlusion may be caused or facilitated by: a) compression of the retinal artery by lymphomatous infiltration of optic nerve, b) direct periarterial tumor infiltration, c) Paraneoplastic hypercoagulability and d) septic emboli in patients with sepsis [14].

Ophthalmoplegias may be due to direct orbital, cavernous sinus, brainstem or menengeal involvement. Cavernous sinus syndrome is rarely seen in lymphomas [15-17]. Because cavernous sinus contains 4 cranial nerves, multiple cranial nerve disfunctions may be seen with pain. The findings of CSF analysis may be normal or abnormal. In this series, cavernous sinus syndrome was detected in two patients. Both suffered severe headache and orbital pain, and total ophthalmoplegia. One of them was the only Hodgkin-type lymphoma of this series. CNS involvement in Hodgkin disease was reported even rarer than non-Hodgkin lymphoma [18].

Paraneoplastic syndromes may be the other cause of neuroophthalmological signs of the lymphomas. Several types of the paraneoplastic syndromes have been described in lymphomas which include: motor neuron disease, cerebellar syndromes and peripheral polyneuropathy [19]. They are believed to be due to an autoimmune mechanism.

In this series, in 10 patients (two patients with optic nerve involvement and 9 patients with ophthalmoplegia), reversal of cranial nerve dysfunction was observed after the radiation or intratechal chemotherapy. In cranial nerve palsies that seen in patients with leukemia or lymphoma, radiation therapy was founded effective despite the absence of infiltration findings on CT or MRI [20].

\section{Conclusion}

In conclusion, systemic lymphomas can cause various neuroophthalmological manifestations. These sometimes occur in a recurrence of systemic lymphoma or as part of the initial presentation of the disease. While these are commonly due to CNS involvement, sometimes it's difficult to determine the etiology. Despite promt and agressive treatment, the prognosis remains poor.

\section{References}

1. Zaman AG, Graham EM, Sanders MD (1993) Anterior visual system involvement in non-Hodgkin lymphoma. Br J Ophthalmol 77(3): 184187.

2. Finelli PF, Lesser RL (1997) Neuroophthalmological presentation of NHL. Neurology 48: 784-785.

3. Newman NJ (1992) Multiple cranial neuropathies Presenting signs of systemic lymphoma. Surv Ophthalmol 37(2): 125-129.

4. Teah R, Barnard RO, Gautier Smith PC (1980) Polyneuritis cranial is as a presentation of malignant lymphoma. J Neurol Sci 48: 399-412.

5. Levy J, Kratz A, Lifshitz T (2006) Burkitt lymphoma presenting as oculomotor palsy in an HIV positive patient. Eur J Ophthalmol 16(1): 186-189.

6. Ing EB (1997) Progressive visual loss and motility deficit. Surv Ophthalmol 41(6): 488-492.

7. Behbehani RS, Vacarezza N, Sergott RC (2005) Isolated optic nerve lymphoma diagnosed by optic nerve biopsy. Am J Ophthalmol 139(6): 1128-1130.

8. Liang H, Luo B, Liu J (2006) Non-Hodgkin lymphoma presenting with ophthalmoplegia and gingival pain. J Neuro Ophthalmol 26(2): 153-154.

9. Bishop PC, Wilson WH, Pearson D, Janik J, Jaffe ES, et al. (1999) CNS involvement in primary mediastinal large B cell lymphoma. J Clin Oncol 17(8): 2479-2485.

10. Herrlinger H, Schabet M, Bitzer M, Petersen D, Krauseneck P (1999) Primary central nervous system lymphoma. From clinical presentation to diagnosis. J Neurooncol 43(3): 219-226. 
11. Kansu T, Orr LS, Savino PJ, Schatz NJ, Corbett JJ (1980) Optic neuropathy as initial manifestation of lymphoreticular diseases: A report of 5 cases. In: Smith JL (Ed.), Neuroophthalmology Focus, pp. 125-136.

12. Saatci OA, Duzovali O, Ozbek Z, Saatci I, Sarialioglu F (1998-1999) Combined retinal artery and vein occlusion in a child with systemic nonHodgkin lymphoma. Int Ophthalmol 22(2): 125-127.

13. Fierz AB, Sartoretti S, Thoelen AM (2001) Optic neuropathy and central retinal artery occlusion in non-Hodgkin lymphoma. J Neuroophthalmol 21(2): 103-105.

14. Guyer DR, Green WR, Schachat AB (1990) Bilateral ischemic optic neuropathy and retinal vascular occlusions associated with lymphoma and sepsis. Ophthalmology 97(7): 882-888.

15. Ceyhan MC, Erdem G, Kanra G (1994) Lymphoma with bilat cavernous sinus involvement in early childhood. Pediatr Neurol 10(1): 67-69.
16. Vaphiades MS, Lee AG (2005) Burkitt lymphoma presenting with gingival pain and a cavernous sinus syndrome in an adult. J Neuroophthalmol 25(3): 249-250.

17. Julien J, Ferrer X, Droullard J, Philippe JC, Desbordes P (1984) Cavernous sinus syndrome due to lymphoma. J Neurol Neurosurg Psychiatr 47(5): 558-560.

18. Kay MC (1986) Optic neuropathy secondary to lymphoma. J Clin Neuroophthalmol 6(1): 31-34.

19. Ascoso FJ, Torres M, Bergua JM, Alvarez R, Cristobal JA (2002) Progressive external ophthalmoplegia: a paraneoplastic manifestation of lymphoma. Eur J Ophthalmol 12(4): 315-318.

20. Ha CS, Chung WK, Koller CA (1999) Role of radiation therapy to the brain in leukemic patients with cranial nerve palsies in the absence of radiological findings. Leuk Lymphoma 32(5-6): 497-503.

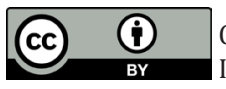

Creative Commons Attribution 4.0 International License

For possible submissions Click Here

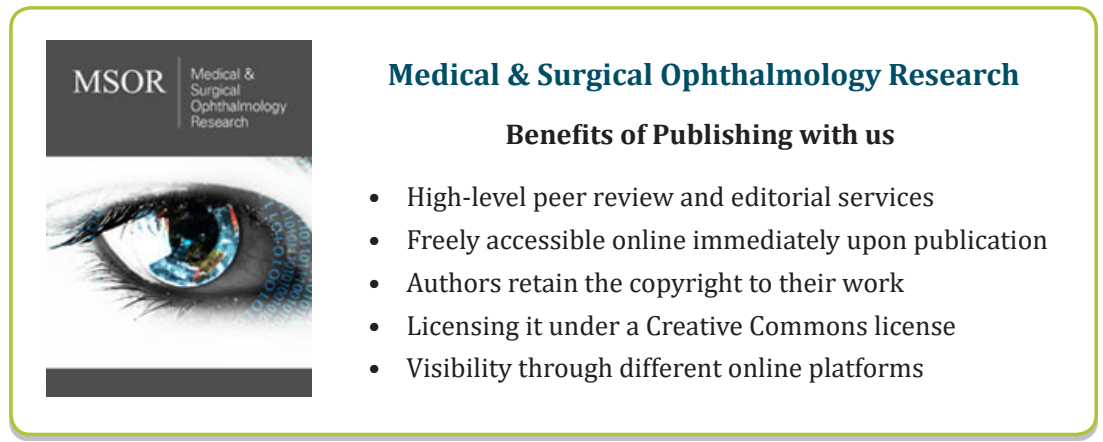

